\title{
Evaluating the responsiveness of the Warwick Edinburgh Mental Well-Being Scale (WEMWBS): Group and individual level analysis
}

\author{
Hendramoorthy Maheswaran ${ }^{1 *}$, Scott Weich², John Powell ${ }^{3}$ and Sarah Stewart-Brown ${ }^{2}$
}

\begin{abstract}
Background: Mental well-being now features prominently in UK and international health policy. However, progress has been hampered by lack of valid measures that are responsive to change. The objective of this study was to evaluate the responsiveness of the Warwick Edinburgh Mental Well-being Scale (WEMWBS) at both the individual and group level.

Methods: Secondary analysis of twelve different interventional studies undertaken in different populations using WEMWBS as an outcome measure. Standardised response mean (SRM), probability of change statistic ( $(\hat{P})$ and standard error of measurement (SEM) were used to evaluate whether WEMWBS detected statistically important changes at the group and individual level, respectively.

Results: Mean change in WEMWBS score ranged from -0.6 to 10.6 . SRM ranged from -0.10 (95\% Cl: $-0.35,0.15)$ to 1.35 (95\% Cl: 1.06, 1.64). In 9/12 studies the lower limit of the $95 \%$ Cl for $\hat{P}$ was greater than 0.5 , denoting responsiveness. SEM ranged from 2.4 to 3.1 units, and at the threshold 2.77 SEM, WEMWBS detected important improvement in at least $12.8 \%$ to $45.7 \%$ of participants (lower limit of $95 \% \mathrm{Cl}>5.0 \%$ ).

Conclusions: WEMWBS is responsive to changes occurring in a wide range of mental health interventions undertaken in different populations. It offers a secure base for research and development in this rapidly evolving field. Further research using external criteria of change is warranted.
\end{abstract}

Keywords: Well-being, WEMBWBS, Responsiveness, Sensitivity to change

\section{Introduction}

Positive mental health and well-being has been of interest to philosophers, social scientists and psychologists for some time. Because of growing awareness of its public health impact [1-6] mental well-being is gradually moving towards centre stage, both in UK and international health policy $[7,8]$. Economists and politicians have also suggested that a 'shift in emphasis from measuring economic production to measuring well-being' is called for because of its potential impact on economic prosperity as well as health [9]. While debate surrounds the precise definitions of both well-being and mental well-being $[10,11]$, there is broad consensus that the latter is more than the absence of mental illness

\footnotetext{
* Correspondence: H.Maheswaran@warwick.ac.uk

'Division of Health Sciences, Warwick Medical School, University of Warwick, Gibbet Hill Campus, Coventry CV4 7AL, UK

Full list of author information is available at the end of the article
}

and that it covers both eudaimonic (psychological functioning) and hedonic (affective) dimensions [12]. This emerging conceptual clarity has led to the development of a number of candidate measures in the research literature.

The Warwick-Edinburgh Mental Well-being Scale (WEMWBS) was developed to measure positive mental health at the population level. Initial psychometric testing showed that the scale was valid, reliable and acceptable in adult populations across Europe [13-16], in adolescents (13-15 years) [17], and in minority ethnic groups [18]. However, a key property of any measure is its responsiveness or sensitivity to change [19]. This is essential for investigating causal pathways, evaluating interventions and assessing the impact of policy at national level. Responsiveness has not yet been established for measures of mental well-being. 
Responsive instruments should have the ability to detect changes in health status where these occur [19]. Several approaches are advocated to evaluate responsiveness [20-22]. Broadly, these are classified as either anchorbased, where an external criterion of change is used to compare the observed changes in scores, or distributionbased, where the observed change is compared to the statistical properties of the sample or instrument [20]. We opted for the latter as our data precluded the former. The literature differentiates the distribution-based methods into whether the instrument is able to detect statistically important changes at the group level or at the individual level [20]. The rationale for undertaking analysis at the individual level is that important changes at the group level may not translate into important changes at the individual level [22]. The objective of this study was to evaluate the wider applicability of WEMWBS. First, we use a combination of both group and individual level measures to evaluate the responsiveness of WEMWBS in a variety of studies undertaken in different populations; and, second, we sought to investigate what change in WEMWBS score may constitute an important change. Our findings provide guidance to investigators using WEMWBS to evaluate the impact of interventions aimed at improving mental wellbeing.

\section{Methods}

\section{Study design}

We undertook secondary analysis of data collected by registered users of WEMWBS. This instrument is available free of charge, but prospective users are asked to register their intended use with the originator of the measure (Sarah Stewart-Brown). An email was sent with a brief questionnaire to all those who had registered to use WEMWBS by asking for a description of their study. Those who replied and who had used one of these measures to evaluate an intervention were contacted. All data comes from users who had registered with the database from November 2007, when the initial validation study of WEMWBS was published [13], to October 2010. During this period 209 groups had registered interest, of these, 34 (16\%) users replied to the email with a description of their study. 15 of the 34 studies used WEMWBS in a before and after study design, the majority $(12 / 15)$ to evaluate a service development, and few studies (3/15) included a control group. We included all studies irrespective of the type of intervention or population studied, but excluded studies with samples of less than 30 participants (3/15), providing data from 12 studies for analysis. We requested anonymised data together with information about the intervention. Few studies (3/12) collected socio-demographic data on participants and this was therefore not investigated. We used secondary data with no participant identifiers, and permission was granted from the lead investigators of the included projects.

\section{The Warwick-Edinburgh Mental Well-being Scale (WEMWBS)}

WEMWBS is a 14-item scale; each answered on a 1 to 5 Likert scale. Items cover different aspects of eudaimonic and hedonic mental wellbeing and are worded positively. Item scores are summed to produce a total score ranging from a minimum of 14 to a maximum of 70 , with higher scores representing higher levels of mental wellbeing.

\section{Data analysis}

Data were imported and analysed in PASW Statistics 18 (SPSS, Chicago, IL, USA), and a user built program was used to display the data as forest plots [23]. Descriptive statistics were used to assess data quality. As we were evaluating the instrument and not the interventions we assumed that data was missing at random [24] and undertook a complete case analysis. We examined floor and ceiling effects in baseline WEMWBS scores. Instruments exhibit floor or ceiling effects if more than $15 \%$ of participants record the lowest or highest score, respectively [25]. Mean and standard deviations of baseline scores were calculated for each study. Normality was verified using the Shapiro-Wilk test and through visual examination of histograms with normal curve, and normality plots.

\section{Group level analysis}

For all the studies we assumed there had been an improvement in mental well-being and investigated whether WEMWBS was able to detect this. We used the standardised response mean (SRM) [26] to evaluate whether WEMWBS was responsive to change at the group-level in each of the studies. The SRM was calculated by dividing the mean change in score by the standard deviation (SD) of the change score [26], and 95\% confidence intervals were constructed by assuming a normal distribution [27]. Although a number of grouplevel statistics have been used in the literature to evaluate responsiveness [22,28], the SRM is considered the most appropriate when evaluating responsiveness in single group pre-post studies [27,29]. SRM was interpreted by calculating the probability of change statistic $\hat{P}$, which represents the cumulative normal distribution function of the derived SRM. The P statistic denotes the probability the instrument detects a change and ranges from 0.5 (no ability to detect change) to 1 (perfect ability to detect change) [27], 95\% CI was estimated using the substitution method [30]. 


\section{Individual level analysis}

At the individual level, any change will consist of true change and the error associated with measurement of the phenomenon in question [20]. A commonly used approach estimates the standard error of measurement (SEM) of the instrument [31] and uses this score to determine whether a statistically important change has been detected at the level of the individual. There is no clear consensus of how much greater than the SEM a change needs to be considered 'true' (statistically), and a variety of thresholds based on the SEM have been proposed ranging from 1 SEM to 2.77 SEM [22]. As our primary objective was to evaluate whether WEMWBS detected statistically important changes at the individual level, we calculated the proportion of participants (and $95 \%$ CI) within each study that would be classified by the instrument as having improved at the higher threshold of 2.77 SEM. A change greater than 2.77 SEM (equal to $1.96 \sqrt{2} \times \mathrm{SEM}$ ) takes into account measurement error, the combined variability across the baseline and post intervention samples, and chance at the $95 \%$ confidence interval $[32,33]$. A measure that is not responsive at the individual level would find less than $2.5 \%$ of the sample to have an increase and $2.5 \%$ to have a decrease in their change score greater than 2.77 SEM, and therefore finding greater than this proportion would suggest WEMWBS was detecting 'true' change at the individual level. The SEM was calculated by multiplying the standard deviation (SD) of the baseline score by the square root of one minus the reliability of the instrument [34]. The statistic used to summarise the reliability of the instrument is either the intraclass correlation coefficient (ICC), obtained from test-retest studies, or Cronbach's alpha [22]. As the reliability of the instrument is sample dependent, we were only able to undertake analysis on studies where item level data for WEMWBS was provided. For each study, Cronbach's alpha was determined using the baseline WEMWBS data.

\section{Results}

Table 1 summarises the twelve included studies: all but one recruited adults and all but three were carried out in general population samples. Table 2 shows that for $4 /$ 12 of the studies the percentage of missing data was over $50 \%$, whilst for $5 / 12$ studies there was no missing data. Studies included ranged in sample size from 33 to 1071,

Table 1 Description of included studies

\begin{tabular}{|c|c|c|c|c|c|}
\hline Evaluators & Population & Age & Sex & Intervention & $\begin{array}{l}\text { Duration of } \\
\text { intervention }\end{array}$ \\
\hline $\begin{array}{l}\text { Perth and Kinross Local } \\
\text { Authority }\end{array}$ & Unpaid carers & Adults & Mixed & $\begin{array}{l}\text { Complementary therapy to support emotional health } \\
\text { and well-being }\end{array}$ & 12 weeks \\
\hline $\begin{array}{l}\text { Foundation for Positive } \\
\text { Mental Health }\end{array}$ & $\begin{array}{l}\text { Healthy self referred working } \\
\text { adults }\end{array}$ & $30-65$ & Mixed & Self help audio intervention & 12 weeks \\
\hline Family Links & Healthy Parents & $30-40$ & Mixed & Group-based parenting programme & 10 weeks \\
\hline $\begin{array}{l}\text { Body and Mind, Coventry } \\
\text { and Warwickshire Mind }\end{array}$ & $\begin{array}{l}\text { Individuals with } \\
\text { schizophrenia, bipolar, } \\
\text { depression and anxiety } \\
\text { disorders }\end{array}$ & Adults & Mixed & $\begin{array}{l}1-1 \text { sessions providing nutritional advice, physical } \\
\text { activity and relaxation therapy }\end{array}$ & 12 weeks \\
\hline $\begin{array}{l}\text { Parenting Early Intervention } \\
\text { Pathfinder (PEIP) }\end{array}$ & $\begin{array}{l}\text { Healthy parents of children } \\
\text { with problem behaviour }\end{array}$ & Adults & Mixed & $\begin{array}{l}\text { Three parenting programmes: Triple P, Incredible Years } \\
\text { and Strengthening Families, Strengthening } \\
\text { Communities }\end{array}$ & 8-12 weeks \\
\hline $\begin{array}{l}\text { Recovery through Healthy } \\
\text { Living Evaluation, Warwick } \\
\text { Medical School }\end{array}$ & $\begin{array}{l}\text { Patients with mental illness } \\
\text { attending psychiatric day } \\
\text { hospital. }\end{array}$ & Adults & Mixed & Recovery programmes & 12 weeks \\
\hline $\begin{array}{l}\text { Up for it? } \\
\text { Lanarkshire }\end{array}$ & Healthy self referred adults & Adults & Mixed & $\begin{array}{l}\text { Health and lifestyle intervention programme offering; } \\
\text { weight management, stress management, physical } \\
\text { activity and stop smoking. }\end{array}$ & 6 weeks \\
\hline $\begin{array}{l}\text { Sligo Sport and Recreation } \\
\text { Partnership }\end{array}$ & Healthy self referred adults & $40-60$ & Mixed & Impact of walking in promoting positive mental health & 8 weeks \\
\hline $\begin{array}{l}\text { PsyWell RCT, Warwick } \\
\text { Medical School }\end{array}$ & Self referred adults & Adults & Mixed & Internet based CBT skills training programme & 5 weeks \\
\hline $\begin{array}{l}\text { Mindfulness in Schools RCT } \\
\text { [43], Cambridge Medical } \\
\text { School }\end{array}$ & Healthy adolescents & $14-15$ & Male & $\begin{array}{l}\text { Mindfulness training covering the principles and } \\
\text { practice of mindfulness meditation. }\end{array}$ & 4 weeks \\
\hline $\begin{array}{l}\text { NHS Mental Health OP } \\
\text { clinic, Bath }\end{array}$ & $\begin{array}{l}\text { Individuals with } \\
\text { Schizophrenia }\end{array}$ & Adults & Mixed & $\begin{array}{l}\text { Provision of Clozapine monitoring services by different } \\
\text { cadres of health professionals }\end{array}$ & 12 weeks \\
\hline $\begin{array}{l}\text { Mental Health Research } \\
\text { Unit, Derby University }\end{array}$ & Healthy recruited adults & Adults & Mixed & $\begin{array}{l}\text { Compassion computer game, involving repeatedly } \\
\text { searching for and finding a compassionate face } \\
\text { amongst an array of distractor faces }\end{array}$ & 1 week \\
\hline
\end{tabular}


Table 2 Comparison of studies included in analysis

\begin{tabular}{|c|c|c|c|c|c|}
\hline \multirow[t]{2}{*}{ Evaluators } & \multirow{2}{*}{$\begin{array}{l}\text { Missing } \\
\text { data } \\
(\%)\end{array}$} & \multirow[t]{2}{*}{$\mathrm{N}^{* *}$} & \multicolumn{2}{|c|}{ Baseline score } & \multirow{2}{*}{$\frac{\text { Change scor }}{\text { Mean (SD) }}$} \\
\hline & & & Mean (SD) & \% Floor/Ceiling & \\
\hline Perth and Kinross Local Authority & 0 & 85 & $39.3(8.9)$ & $1.2 / 1.2$ & $10.6(7.8)$ \\
\hline Foundation for Positive Mental Health & 50 & 50 & $44.6(8.0)$ & $1.0 / 2.0$ & $5.7(6.3)$ \\
\hline Family Links & 0 & 153 & $42.6(9.4)$ & $0.7 / 0.7$ & $7.3(8.4)^{*}$ \\
\hline Body and Mind, Coventry and Warwickshire Mind & 9 & 145 & $40.3(9.2)$ & $0.6 / 0.6$ & $6.2(8.3)^{*}$ \\
\hline Parenting Early Intervention Pathfinder (PEIP) & 50 & 1071 & $43.5(10.4)^{*}$ & $0.1 / 0.5$ & $7.2(9.9)^{*}$ \\
\hline Recovery through Healthy Living Evaluation, Warwick Medical School & 20 & 42 & $34.0(7.7)$ & $1.4 / 1.4$ & $8.1(11.3)^{*}$ \\
\hline Up for it? & 62 & 404 & $42.2(10.8)$ & $0.2 / 0.2$ & $7.0(10.2)^{*}$ \\
\hline \multicolumn{6}{|l|}{ Lanarkshire } \\
\hline Sligo Sport and Recreation Partnership & 0 & 33 & $51.6(9.6)$ & $3.0 / 3.0$ & $3.8(7.7)^{*}$ \\
\hline PsyWell RCT, Warwick Medical School & 64 & 557 & $42.5(9.4)^{*}$ & $0.4 / 0.2$ & $2.3(7.7)^{*}$ \\
\hline Mindfulness in Schools RCT [43], Cambridge Medical School & 27 & 78 & $49.7(6.0)$ & $0.7 / 0.7$ & $1.2(6.1)^{*}$ \\
\hline NHS Mental Health OP clinic, Bath & 0 & 33 & $44.6(10.7)$ & $3.0 / 9.1$ & $0.1(9.6)^{*}$ \\
\hline Mental Health Research Unit, Derby University & 0 & 61 & $50.4(8.4)$ & $1.6 / 3.3$ & $-0.6(6.5)$ \\
\hline
\end{tabular}

${ }^{*} \mathrm{P}<0.05$ for Shapiro-Wilk test for normality.

**available for complete case analysis.

with 9/12 studies providing data on 50 or more participants. In all of the studies, fewer than $15 \%$ of participants demonstrated either a floor or ceiling effect. Baseline mean WEMWBS scores were generally lower than that found in the initial population study (mean=50.7) [13], suggesting preferential recruitment to intervention studies of those with lower mental wellbeing. For baseline WEMWBS scores the Shapiro-Wilk test was non-significant except in two studies (PEIP and PsyWell), for change scores the Shapiro-Wilk test was significant in the majority of the studies. However, visual examination of histograms and normality plots of both baseline and changes scores approximated to normal distribution (data available from authors upon request), suggesting the data did not violate the normality assumption.

Figure 1 shows the SRM and Figure 2 the probability of change statistic $\hat{P}$ for all twelve studies. The SRM ranged from $-0.10(95 \% \mathrm{CI}:-0.35,0.15)$ to 1.35 (95\% CI: $1.06,1.64)$, and the probability of change statistic $\hat{P}$

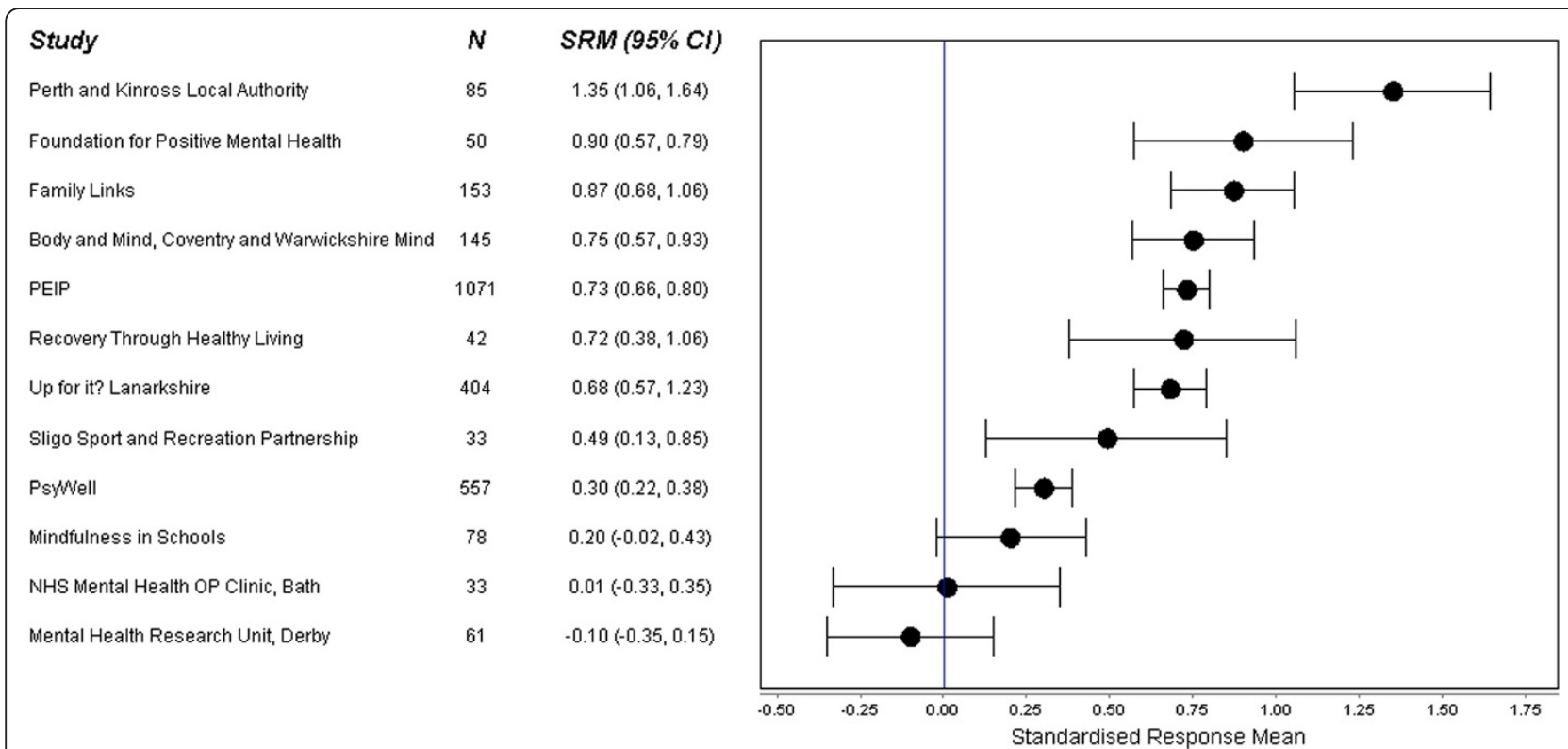

Figure 1 Forest Plot with Standardised response mean (SRM) for included studies. 


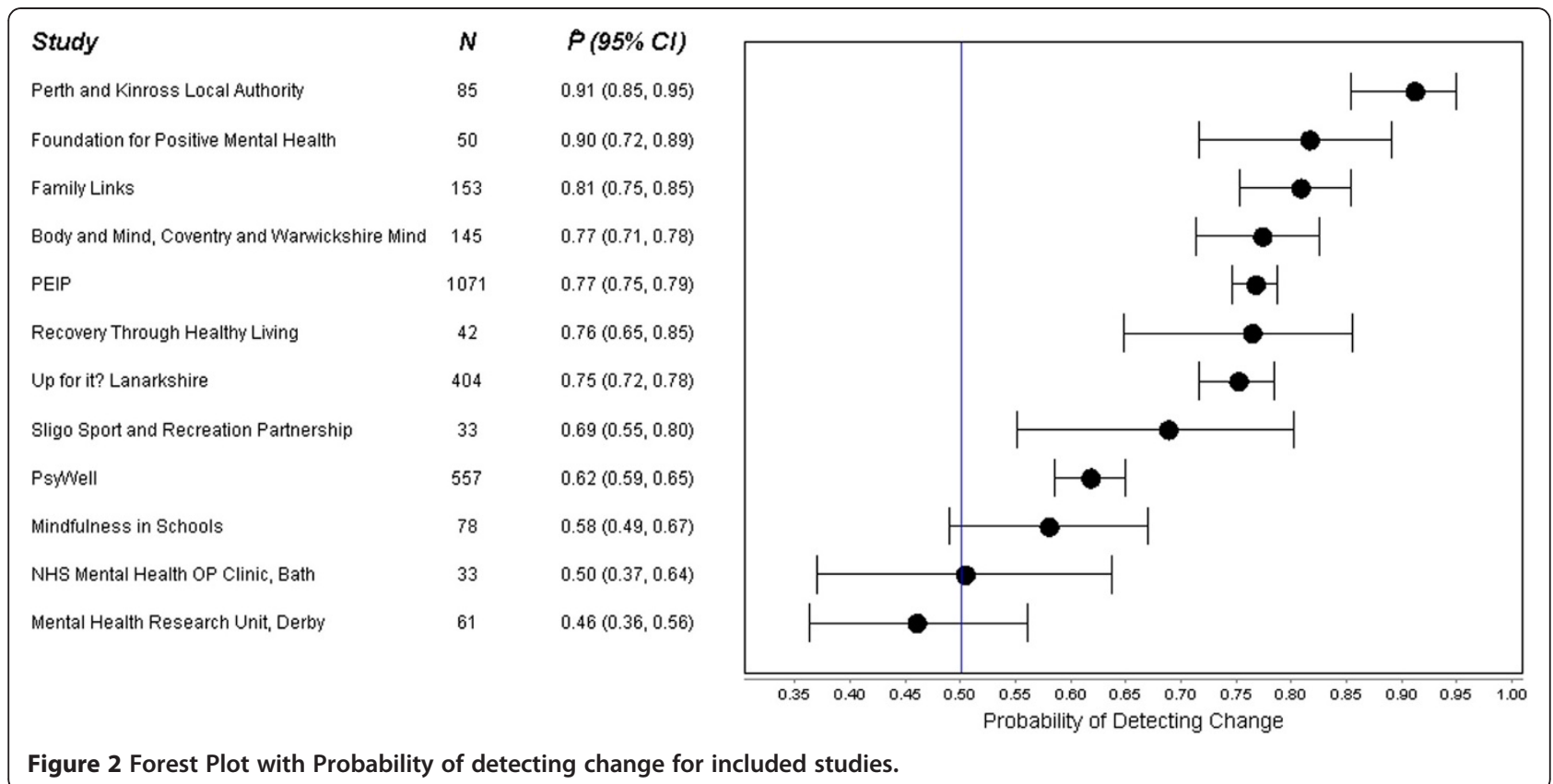

ranged from 0.46 (95\% CI: $0.36,0.56)$ to 0.91 (95\% CI: $0.85,0.95)$. In nine of the studies the lower limit of the $95 \%$ CI for $\hat{P}$ was greater than 0.5 , whilst in six of the studies, the lower limit of the $95 \% \mathrm{CI}$ for $\hat{\mathrm{P}}$ was greater than 0.7 . There was no evidence of any association between sample size and SRM.

Table 3 shows the findings from the individual level analysis. Of the twelve studies, item data for WEMWBS was only available for five: four undertaken in an adult population and one undertaken in an adolescent population (Mindfulness in Schools). Cronbach's alpha for the four studies in the adult population was $\geq 0.864$ and for the one study in the adolescent population was 0.733 . The SEM for the four studies in the adult population ranged from 2.4 to 2.8 , and for the one study in the adolescent population was 3.1. At the 2.77 SEM threshold $12.8 \%$ to $45.7 \%$ (lower limit of $95 \%$ CI $>5.0 \%$ ) of participants in the studies were found to demonstrate an increase in their score.

\section{Discussion}

This is the first study of which we are aware to evaluate the responsiveness of a mental well-being measure at both group and individual level. The study was possible because of the popularity and uptake of WEMWBS in evaluating interventions designed to improve mental well-being. Although WEMWBS was developed to measure mental well-being at the group or population level there has also been demand from investigators to use the scale at the individual level. It is important therefore that we found WEMWBS to be responsive at both levels. Responsiveness was independent of the type of intervention and sample size, and whilst we cannot know with certainty whether the interventions delivered in the different studies were effective, our results suggest that WEMWBS is responsive in relatively small samples. WEMWBS is likely to be responsive because it evaluates individual mental well-being across both the eudaimonic

Table 3 Evaluation of individual level responsiveness

\begin{tabular}{lccccc}
\hline Evaluators & N & Cronbach alpha & 1 SEM & $\begin{array}{c}\text { 2.77 SEM } \\
\text { \% Improved at 2.77 } \\
\text { SEM (95\% Cl) }\end{array}$ \\
\hline Recovery through Healthy Living Evaluation, Warwick Medical School & 42 & 0.864 & 2.84 & 7.87 & $45.2(30.2,60.3)$ \\
\hline Parenting Early Intervention Pathfinder (PEIP) & 1071 & 0.926 & 2.83 & 7.85 & $45.7(42.7,48.6)$ \\
\hline PsyWell RCT, Warwick Medical School & 557 & 0.938 & 2.35 & 6.51 & $27.7(23.9,31.4)$ \\
\hline Mindfulness in Schools RCT [43], Cambridge Medical School* & 78 & 0.733 & 3.09 & 8.55 & $12.8(5.4,20.2)$ \\
\hline NHS Mental Health OP clinic, Bath & 33 & 0.933 & 2.77 & 7.69 & $18.2(5.1,31.3)$ \\
\hline
\end{tabular}

*Study undertake in Adolescents.

SEM: Standard Error of Measurement.

$\mathrm{Cl}$ : Confidence Interval. 
and hedonic dimensions, and is therefore more able to detect changes in their mental well-being.

When evaluating responsiveness at the group level through distribution-based approaches, the SRM is considered the most appropriate statistic [27]. However, in the literature a variety of statistics have been used to evaluate responsiveness at the group-level, including the paired $t$-test [35] and Cohen's effect size (mean change in score by the standard deviation of the baseline score) [36]. In contrast to the paired t-test, the SRM is a sample size free statistic and therefore allowed us to compare responsiveness in studies of different sample sizes. Cohen's effect size is dependent on between-subject variability, whilst the SRM is dependent on within-subject variability[37]. As our objective was to evaluate responsiveness of WEMWBS in detecting within-subject change we choose the SRM. Interestingly, the similarity in the standard deviation of the baseline and change WEMWBS scores in the studies evaluated means that Cohen's effect size will be comparable to the SRM for each study.

In the majority of studies the SRM was greater than 0.5. This compares favourably to other mental illness and life satisfaction scales [38-40], generic health-related quality of life scales [41], and disease specific scales [42]. We found WEMWBS demonstrated minor floor or ceiling effects $(<5 \%)$, considerably less than the $15 \%$ threshold which has been proposed [25], and to be responsive in studies undertaken in those with and without underlying mental health problems. This contrasts with mental illness scales that tend to be more responsive in populations with mental health problems [38]. Although in the majority of studies the mean baseline score was below previously reported population norms, these findings suggest that WEMWBS has the capacity to detect change in populations with both good and poor mental health, and to detect subtle improvements.

In evaluating the significance of the SRM we determined the probability of change statistic $\hat{P}$ as it provides a very intuitive interpretation of responsiveness at the group-level. A value of 0.5 suggests that if a change has occurred the instrument is as equally likely to have detected the change, as it is to have not detected the change, and therefore is not responsive. For the majority of the studies, we found the probability of change statistic $\hat{P}$ to be above 0.7 , suggesting WEMWBS is responsive at the group level [27]. We assumed that in all the studies the interventions were effective at improving mental well-being. The fact that WEMWBS was not responsive at the group level in all studies could be because the interventions were not effective or because WEMWBS is not responsive to change in those populations. Only one study was undertaken in an adolescent population (Mindfulness in Schools [43]). In this study, WEMWBS was not found to be responsive. The test-retest reliability coefficient for WEMWBS in the validation study undertaken in an adolescent population (0.66) [17] was lower than the corresponding coefficient in the validation study undertaken in an adult population (0.83) [13]. It is possible that WEMWBS may not be as responsive to change in adolescents, however, further research is needed to investigate this and whether participant characteristics impact on the responsiveness of WEMWBS.

In the five studies where item level data was available, we found WEMWBS performed reasonably well in detecting change at the individual level. There is as yet no agreed consensus on what constitutes an important change at the individual level, with some suggesting that a change score greater than 1 SEM is important [34], whilst others suggest 2.77 SEM [32]. In all five studies, we found at the higher threshold of 2.77 SEM, the lower limit of the $95 \%$ confidence interval for the proportion of individuals classified as improved was greater than the $2.5 \%$ expected if WEMWBS was not responsive at the individual level. An important finding from the individual level analysis was the relatively stable Cronbach's alpha score in adult populations. In the four studies undertaken in an adult population, the Cronbach's alpha score was consistently high and comparable to the validation study undertaken in the adult population [13]. In the one study undertaken in the adolescent population, WEMWBS demonstrated satisfactory internal consistency [44], however, the Cronbach's alpha score was lower than that found in the validation study undertaken in an adolescent population [17].

It has been suggested that the SEM of a measure is independent of the sample [34]. It was note-worthy to find that across the five studies for which item level data was available, the SEM was relatively comparable, suggesting that a single change in WEMWBS score could be applied to classify individuals as improved. Previous literature suggests that an improvement of 0.5 units on each item on a Likert scale would equate to an improvement deemed important by individuals [45]. This makes intuitive sense and equates to an overall change score of 7 . In the studies evaluated we found a change score of 8 or more equated to statistical importance at the higher threshold of 2.77 SEM. However, a change of 3 or more units (1 SEM) in an individual's WEMWBS score was greater than the measurement error in the majority of the studies, and thus could be interpreted as important. Further research with comparison to self-reported global ratings of change (GRC) is warranted.

Our conclusions are potentially limited, mainly as a consequence of the data used. We used data from registered users who had replied to our request to use their data, assumed that data was missing at random and only looked at change in those who had undergone an 
intervention. It is possible, in contravention of copyright, that there are users of WEMWBS who had not registered their use on our database. It is also possible that the reason registered users had not replied to our request was because they had not found a positive finding in their study. It is possible that missing postintervention WEMWBS scores were not missing at random. This may potentially lead to biased estimates of treatment effect, however, our objective was to determine whether WEMWBS could detect changes in individuals' mental well-being had they occurred. In evaluating responsiveness, it is this within-person change that is considered relevant [22]. We use distributionbased approaches to evaluate responsiveness to the exclusion of the anchor-based approaches that are increasingly favoured. Anchor-based evaluation requires a GRC. These have been associated with limitations including recall-bias, lack of validity, and are possibly insensitive to prospectively evaluated change $[27,29]$. Importantly, GRCs have been used in evaluating instruments measuring physical health. Whether they have construct validity in denoting improvement in mental well-being is not yet known, and therefore anchor-based approaches may not be appropriate. It is also widely acknowledged that where GRCs are not available, statistical approaches to evaluating responsiveness are valid [21,22,27,28,37]. As with any population measure, some of the changes observed may represent regression to the mean. The fact that change was observed in population groups with average as well as those with low baseline scores suggests that not all change can be attributed to this phenomenon.

\section{Conclusion}

The relative scarcity of instruments with sufficient evidence of validity, reliability acceptability to measure mental well-being has hindered the development of policy and practice in mental health promotion. WEMWBS is a valid, reliable and acceptable measure [13], which we have demonstrated, is responsive to change in a wide variety of settings from the community settings, to schools, and psychiatric hospitals, making it suitable for use in evaluation of interventions at group and individual level. It therefore offers great potential to further research and development on mental well-being.

\section{Competing interests}

There are no conflicts of interest regarding the contents of this article. This research would not have been possible without support from NHS Health Scotland to maintain a database of users of WEMWBS. We received no specific grant from any funding agency in the public, commercial or not-forprofit sectors for the analysis of this data.

\section{Authors' contributions}

$\mathrm{HM}$ and SSB designed the study, analysed the data and drafted the manuscript. SWP and JP aided in interpretation of data and critical revision of the manuscript. All authors contributed to final manuscript and approved the decision to submit the manuscript.

\section{Acknowledgements}

The development of the Warwick-Edinburgh Mental Well-being scale (WEMWBS), was commissioned by NHS Health Scotland, funded by the Scottish Executive National Programme for improving mental health and well-being, and undertaken by the University of Warwick and the University of Edinburgh. The scale is jointly owned by NHS Health Scotland, the University of Warwick and the University of Edinburgh. It is available free of charge, but prospective users are required to register use with frances. taggart@warwick.ac.uk or sarah.stewart-brown@warwick.ac.uk. WEMWBS development involved the support of a team of experts. Professor Steve Platt from the University of Edinburgh and Jane Parkinson from NHS Health Scotland in particular have played a vital and on going supportive role in development and validation. NHS Health Scotland contributes funding to support the maintenance of the database of WEMWBS users which provided the starting point for this study.

We want to thank all the investigators (and their respective organisations) who provided data: Professor Felicia Huppert (University of Cambridge); Dr Denise Taylor and Dr Jane Sutton (University of Bath); Mary Chapman (Perth and Kinross Local Authority); Jayne Orrill (Coventry and Warwickshire Mind); Professor Paul Gilbert and Kirsten Mcewan (Mental Health Research Unit, Derby); Susan McMorrin (Up for it? Lanarkshire); Gina Hocking (Family Links); Professor Steve Strand and Professor Geoff Lindsay (University of Warwick); Shane Hayes (Sligo Sport and Recreation Partnership); Shelia Ross (University of Edinburgh); Dr Anca Alba (University of Warwick). Without their hard work and support this study would not have been possible.

\section{Author details}

'Division of Health Sciences, Warwick Medical School, University of Warwick, Gibbet Hill Campus, Coventry CV4 7AL, UK. ²Division of Mental Health and Wellbeing, Warwick Medical School, University of Warwick, Gibbet Hill Campus, Coventry CV4 7AL, UK. ${ }^{3}$ Department of Primary Care Health Sciences, University of Oxford, Oxford, United Kingdom.

Received: 28 August 2012 Accepted: 13 December 2012 Published: 27 December 2012

\section{References}

1. Levy SM, Lee J, Bagley C, Lippman M: Survival hazards analysis in first recurrent breast cancer patients: seven-year follow-up. Psychosom Med 1988, 50:520-528.

2. Devins GM, Mann J, Mandin H, Paul LC: Psychosocial predictors of survival in end-stage renal disease. J Nerv Ment Dis 1990, 178:127-133.

3. Huppert FA, Whittington JE: Symptoms of psychological distress predict 7-year mortality. Psychol Med 1995, 25:1073-1086.

4. Snowdon D: Aging with grace: What the nun study teaches us about leading longer, healthier, and more meaningful lives. New York: Bantam; 2002.

5. Chida Y, Steptoe A: Positive psychological well-being and mortality: a quantitative review of prospective observational studies. Psychosom Med 2008, 70:741-756.

6. Ford J, Spallek M, Dobson A: Self-rated health and a healthy lifestyle are the most important predictors of survival in elderly women. Age Ageing 2008, 37:194.

7. WHO: Promoting mental health: concepts, emerging evidence, practice. 2005, Available at: http://www.who.int/mental_health/evidence/ MH_Promotion_Book.pdf.

8. DoH: No health without mental health: a cross-government mental health outcomes strategy for people of all ages. 2011, Available at: http://www.dh.gov.uk/prod_consum_dh/groups/dh_digitalassets/ documents/digitalasset/dh_124058.pdf.

9. Stiglitz J, Sen A, Fitoussi JP: Report by the commission on the measurement of economic performance and social progress. 2009, Available at: http://www.stiglitz-sen-fitoussi.fr/documents/rapport_anglais. pdf.

10. Huppert F, Whittington J: Evidence for the independence of positive and negative well-being: Implications for quality of life assessment. Br J Health Psychol 2003, 8:107-122. 
11. Keyes CL: Mental illness and/or mental health? Investigating axioms of the complete state model of health. J Consult Clin Psychol 2005, 73:539-548.

12. Ryan RM, Deci EL: On happiness and human potentials: A review of research on hedonic and eudaimonic well-being. Annu Rev Psychol 2001, 52:141-166.

13. Tennant R, Hiller L, Fishwick R, Platt S, Joseph S, Weich S, Parkinson J, Secker J, Stewart-Brown S: The Warwick-Edinburgh Mental Well-being Scale (WEMWBS): development and UK validation. Health Qual Life Outcomes 2007, 5:63.

14. Lloyd K, Devine P: Psychometric properties of the Warwick-Edinburgh Mental Well-being Scale (WEMWBS) in Northern Ireland. J Ment Health 2012, 21:257-263.

15. López MA, Gabilondo A, Codony M, García-Forero C, Vilagut G, Castellví P. Ferrer M, Alonso J: Adaptation into Spanish of the Warwick-Edinburgh Mental Well-being Scale (WEMWBS) and preliminary validation in a student sample. Qual Life Res 2012, 1-6.

16. Gremigni $P$, Stewart-Brown SL: Measuring mental well-being: Italian validation of the Warwick-Edinburgh Mental Well-Being Scale (WEMWBS). Giornale Italiano di Psicologia 2011, :485-508.

17. Clarke A, Friede T, Putz R, Ashdown J, Martin S, Blake A, Adi Y, Parkinson J, Flynn P, Platt S, Stewart-Brown S: Warwick-Edinburgh Mental Well-being Scale (WEMWBS): validated for teenage school students in England and Scotland. A mixed methods assessment. BMC Public Health 2011, 11:487.

18. Stewart-Brown S: The Warwick-Edinburgh Mental Well-being Scale (WEMWBS): performance in different cultural and geographical groups. In Mental Well-being: International Contributions to the Study of Positive Mental Health. Edited by Keyes CL: Springer; 2011.

19. Guyatt $G$, Walter $S$, Norman $G$ : Measuring change over time: assessing the usefulness of evaluative instruments. J Chronic Dis 1987, 40:171-178.

20. Crosby RD, Kolotkin RL, Williams GR: Defining clinically meaningful change in health-related quality of life. J Clin Epidemiol 2003, 56:395-407.

21. Husted JA, Cook RJ, Farewell VT, Gladman DD: Methods for assessing responsiveness: a critical review and recommendations. J Clin Epidemiol 2000, 53:459-468.

22. Beaton DE, Bombardier C, Katz JN, Wright JG: A taxonomy for responsiveness. J Clin Epidemiol 2001, 54:1204-1217.

23. Boyles AL, Harris SF, Rooney AA, Thayer KA: Forest Plot Viewer: a new graphing tool. Epidemiology 2011, 22:746-747.

24. Pigott TD: A review of methods for missing data. Educ Res Eval 2001, 7:353-383.

25. McHorney CA, Tarlov AR: Individual-patient monitoring in clinical practice: are available health status surveys adequate? Qual Life Res 1995 4:293-307.

26. Liang MH, Fossel AH, Larson MG: Comparisons of five health status instruments for orthopedic evaluation. Med Care 1990, 28:632-642.

27. Zou GY: Quantifying responsiveness of quality of life measures without an external criterion. Qual Life Res 2005, 14:1545-1552.

28. Terwee CB, Dekker FW, Wiersinga WM, Prummel MF, Bossuyt PM: On assessing responsiveness of health-related quality of life instruments: guidelines for instrument evaluation. Qual Life Res 2003, 12:349-362.

29. Stratford PW, Riddle DL: Assessing sensitivity to change: choosing the appropriate change coefficient. Health Qual Life Outcomes 2005, 3:23.

30. Daly LE: Confidence limits made easy: interval estimation using a substitution method. Am J Epidemiol 1998, 147:783-790.

31. Stratford PW, Binkley J, Solomon P, Finch E, Gill C, Moreland J: Defining the minimum level of detectable change for the Roland-Morris questionnaire. Phys Ther 1996, 76:359-365. discussion 366-358.

32. Jacobson NS, Truax P: Clinical significance: a statistical approach to defining meaningful change in psychotherapy research. J Consult Clin Psychol 1991, 59:12-19.

33. Christensen $L$, Mendoza $\mathrm{J}$ : $A$ method of assessing change in a single subject: An alteration of the RC index. Behav Ther 1986, 17:305-308.

34. Wyrwich KW, Tierney WM, Wolinsky FD: Further evidence supporting an SEM-based criterion for identifying meaningful intra-individual changes in health-related quality of life. J Clin Epidemio/ 1999, 52:861-873.

35. Liang MH, Larson MG, Cullen KE, Schwartz JA: Comparative measurement efficiency and sensitivity of five health status instruments for arthritis research. Arthritis Rheum 1985, 28:542-547.

36. Kazis LE, Anderson JJ, Meenan RF: Effect sizes for interpreting changes in health status. Med Care 1989, 27:S178-S189.
37. Norman GR, Wyrwich KW, Patrick DL: The mathematical relationship among different forms of responsiveness coefficients. Qual Life Res 2007 $16: 815-822$

38. Hevey D, McGee HM, Horgan J: Responsiveness of health-related quality of life outcome measures in cardiac rehabilitation: comparison of cardiac rehabilitation outcome measures. J Consult Clin Psychol 2004, 72:1175-1180

39. Boyer P, Montgomery S, Lepola U, Germain JM, Brisard C, Ganguly R, Padmanabhan SK, Tourian KA: Efficacy, safety, and tolerability of fixeddose desvenlafaxine 50 and $100 \mathrm{mg} /$ day for major depressive disorder in a placebo-controlled trial. Int Clin Psychopharmacol 2008, 23:243-253.

40. Christensen KS, Bech P, Fink P: Measuring Mental Health by Questionnaires in Primary Care - Unidimensionality. Responsiveness and Compliance. Eur Psychiatr Rev 2010, 3:8-12.

41. Lamers LM, Bouwmans CA, van Straten A, Donker MC, Hakkaart L: Comparison of EQ-5D and SF-6D utilities in mental health patients. Health Econ 2006, 15:1229-1236.

42. Wiebe S, Guyatt G, Weaver B, Matijevic S, Sidwell C: Comparative responsiveness of generic and specific quality-of-life instruments. J Clin Epidemiol 2003, 56:52-60.

43. Huppert FA, Johnson DM: A controlled trial of mindfulness training in schools: The importance of practice for an impact on well-being. The Journal of Positive Psychology: Dedicated to furthering research and promoting good practice 2010, 5:264-274.

44. Cronbach $\bigsqcup$ : Coefficient alpha and the internal structure of tests. Psychometrika 1951, 16:297-334.

45. Jaeschke R, Singer J, Guyatt GH: Measurement of health status. Ascertaining the minimal clinically important difference. Control Clin Trials 1989, 10:407-415

doi:10.1186/1477-7525-10-156

Cite this article as: Maheswaran et al:: Evaluating the responsiveness of the Warwick Edinburgh Mental Well-Being Scale (WEMWBS): Group and individual level analysis. Health and Quality of Life Outcomes 2012 10:156.

\section{Submit your next manuscript to BioMed Central and take full advantage of:}

- Convenient online submission

- Thorough peer review

- No space constraints or color figure charges

- Immediate publication on acceptance

- Inclusion in PubMed, CAS, Scopus and Google Scholar

- Research which is freely available for redistribution

Submit your manuscript at www.biomedcentral.com/submit
C BioMed Central 